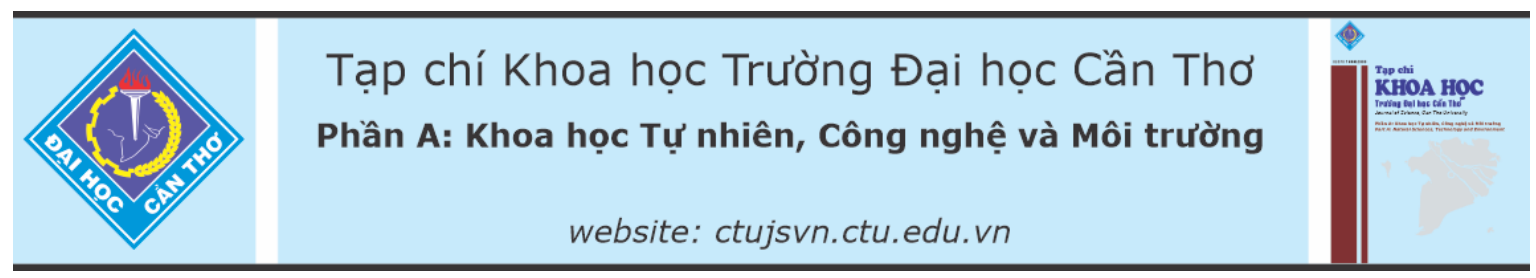

DOI:10.22144/ctu.jvn.2021.168

\title{
PHÂN TÍCH XU HƯỚNG PHÁT TRIỂN ĐÔ THỊ THÀNH PHỐ CẦN THƠ GIAI ĐOẠN 2004 - 2019
}

Nguyễn Thị Hồng Điệp ${ }^{1 *}$, Nguyễn Trọng Cần ${ }^{2}$, Phan Kiều Diễm ${ }^{1}$, Nguyễn Xuân Hoàng $^{1}$ và Bùi Hoàng Phúc ${ }^{3}$

${ }^{1}$ Bộ môn Tài nguyên đất đai, Khoa Môi truờng và Tài nguyên Thiên nhiên, Trường Đại học Cần Tho'

${ }^{2}$ Học viên Cao họ ngành Quản lý đất đai K23, Truờng Đại học Cần Tho

${ }^{3}$ Sinh viên ngành Quản lý đất đai K42, Truờng Đại học Cần Tho

*Nguò̀i chịu trách nhiệm về bài viết: Nguyễn Thị Hồng Điệp (email: nthdiep@ctu.edu.vn)

\section{Thông tin chung:}

Ngày nhận bài: $24 / 06 / 2021$

Ngày nhận bài sủa: 11/09/2021

Ngày duyệt đăng: 25/12/2021

Title:

Analyzing urban development trends in Can Tho city in 2004 $-2019$

\section{Tù khóa:}

Ảnh Landsat, thành phố Cần Tho, tốc độ đô thị hóa, xu hướng đô thị hóa

\section{Keywords:}

Can Tho city, Landsat image, urbanization rate, urban trend

\section{ABSTRACT}

The study was analyzed and evaluated the trend of urban growth in 2004 and 2019 supporting localities in planning urban development orientations in Can Tho city. Landsat images were applied using the Maximum Likelihood Classifier (MCL) classification to map the land uselland cover in Can Tho city and hotspot analysis to explore the urbanization trend. The results revealed that urban areas are mainly concentrated in Cai Rang, Ninh Kieu, Binh Thuy, and Thot Not districts. The urban area in 2004 was 6,400.2 hectares (ha) and 16,007.0 ha in 2019. The urban proportion increased from $4.45 \%$ to $11.12 \%$. The average annual urbanization rate in the whole city was $0.43 \% / y e a r$ in which the highest rate in Ninh Kieu district at 1.52\%/year and the lowest rate in Co Do district at 0.19\%/year. Urban density in Ninh Kieu district is the highest value with 45.9\% in 2004 and 65.62\% in 2019. The urbanization trends forming residential chains were along the Hau river, the Can Tho river toward the southeast and main national highways.

\section{TÓM TẮT}

Nghiên cưu được thưc hiện nhằm phân tích và đánh giá xu hướng phát triển đô thi thành phố (TP.) Cần Tho năm 2004 và 2019 tù đó hố trợ các địa phuoong định huoóng phát triển vùng đô thị tại các quân/huyện TP. Cần Tho: Anh Landsat được phân loại bằng thuật toán xác suất cực đại (Maximum Likelihood Classification-MCL) và phân tích điểm nóng (Hotspot) theo dõi xu huoóng đô thị hóa. Kết quả nghiên cứu cho thấy đô thị tập trung chủ yếu tại 4 quận Cái Răng, Ninh Kiều, Bình Thủy và Thốt Nốt với tổng diện tích năm 2004 là 6.400,2 héc-ta (ha) và năm 2019 là 16.007,0 ha. Tỷ lẹ đô thị của TP. Cần Tho tăng tù 4,45\% năm 2004 lên 11,12\% năm 2019. Tốc độ đô thị hóa trung bình năm của toàn thành phố là $0,43 \%$, cao nhất là quận Ninh Kiều với $1,52 \%$ và thấp nhất là $0,19 \%$ ơ huyện Cờ Đỏ. Mật độ đô thị quận Ninh Kiều cao nhất toàn thành phố với 45,9\% năm 2004 và 65,62\% năm 2019. Đô thị hóa phát triển theo huớng (1) dọc theo sông Hậu hìn thành một đô thị dạng chuỗi, (2) theo sông Cần Tho về phía Tây Nam và (3) theo huớng các tuyến quốc lộ chính. 


\section{1. ĐẶT VẤN ĐỀ}

Quá trình đô thị hóa mạnh mẽ cùng với sự gia tăng dân số đã dẫn tới sự thay đổi lớn trong hiện trạng sử dụng đất ở hầu hết các tỉnh thành ở Việt Nam, đặc biệt là tại các thành phố lớn. Theo Bộ Xây dựng (2019), cả nước có 630 đô thị với tỷ lệ đô thị hóa khoảng $27 \%$ đã tăng lên 819 đô thị vào năm 2018 với tỷ lệ đô thị hóa $38,4 \%$, trung bình mỗi năm tỷ lệ đô thị hóa tăng trên dưới $1 \%$ tương ứng với dân số đô thị gia tăng mỗi năm khoảng 1 triệu người. Đến năm 2025, tỷ lệ đô thị hóa dự kiến đạt 45-50\% với khoảng 1.000 đô thị, dân số đô thị khoảng 52 triệu người. Đô thị hóa nhanh chóng dẫn đến tình trạng các khu đô thị tập trung dân số cao cùng các hạ tầng đô thị dày đặc là nguyên nhân gây nên các khu vực dễ tổn thương tại các trung tâm đô thị. Các vấn đề thường gặp ở đô thị rất đa dạng từ việc thiếu việc làm, nghèo đói đô thị, phân cấp xã hội, mù chữ, mất an ninh trật tự xã hội và nhiều vấn đề môi trường khác (Peng et al., 2010; Sintusingha, 2011). Những vấn đề này đòi hỏi cần phải có kế hoạch lâu dài nhằm đảm bảo quá trình đô thị hóa diễn ra có hiệu quả.

Cần Thơ là thành phố giàu tiềm năng, có lịch sử hình thành khá lâu đời, giữ vai trò rất quan trọng cả về kinh tế - xã hội và quốc phòng - an ninh, là động lực phát triển của vùng Đồng bằng sông Cửu Long (ĐBSCL). Ngày 26/11/2003, QH khóa 11 đã ban hành Nghị quyết số 22/2003/QH11 chia tỉnh Cần Thơ thành TP Cần Thơ trực thuộc Trung ương (TW) và tỉnh Hậu Giang. Qua đó TPCT trực thuộc TW được chính thức thành lập ngày $01 / 01 / 2004$; và một ngày sau, ngày 02/01/2004 Chính phủ ban hành Nghị định số 05/2004/NĐ-CP về việc thành lập các quận/huyện, xã/phường/thị trấn của TPCT. Đến nay thành phố Cần Thơ (TP. Cần Thơ) có mật độ dân số cao khoảng 858 người $/ \mathrm{km}^{2}$, xếp 12/63 và cao gấp 3 lần mật độ dân số trung bình toàn quốc (290 người $/ \mathrm{km}^{2}$ ); và cao gấp 2 lần mật độ dân số $\mathrm{BSCL}$ (423 người $/ \mathrm{km}^{2}$ ). Trong đó, dân cư thành thị là 860.557 người (chiếm 69,67\%) (Cục Thống kê TP. Cần Thơ, 2020). Qua 15 năm phát triển (2005 2019), tốc độ mở rộng đô thị ở TP. Cần Thơ diễn ra nhanh chóng, kết cấu hạ tầng đô thị dần được đồng bộ, tạo nên những thế mạnh trong phát triển kinh tế - xã hội. Song, tiến trình đô thị hoá, công nghiệp hoá, đã và đang tồn tại nhiều bất cập, ảnh hưởng đến đời sống nhân dân: tình trạng ngập lụt đô thị, ô nhiễm môi trường, ùn tắc giao thông, công tác quản lý dân cư vẫn còn nhiều bất cập.

Hiện nay, các nhà hoạch định và ra quyết định thành phố đang tính đến áp dụng các kỹ thuật hiện đại như hệ thống thống tin địa lý (GIS) và viễn thám
(RS) khi họ muốn xây dựng các chính sách trong tương lai (Liu et al., 2015). GIS và RS đang được xem xét vì thực tế kỹ thuật này có các chiều không gian và thời gian để theo dõi, kiểm soát, phân tích, đánh giá và đo lường các mô hình tăng trưởng đô thị và thay đổi sử dụng đất (Liu et al., 2015; Ramachandra et al., 2013). Ngoài ra, các kỹ thuật này có thể sử dụng các phương pháp định lượng và định tính để xác định nguyên nhân, tác động và xu hướng hiện tại và tương lai của các mô hình tăng trưởng đô thị (Aithal \& Sanna, 2012; Al-shalabi et al., 2013; Shalaby, 2012; Yang, 2010). Dữ liệu kinh tế xã hội và không gian có thể được tích hợp bằng cách sử dụng các kỹ thuật RS và GIS để phân tích các mô hình thay đổi sử dụng đất phức tạp. Hơn nữa, các phương trình toán học, chẳng hạn như phương trình phân tích sự hỗn tạp của Shannon và các thước đo cảnh quan có thể được sử dụng trong môi trường RS và GIS để xác định các loại hình đô thị (Aithal \& Sanna, 2012; Ramachandra et al., 2013; Yang, 2010).

Bên cạnh đó, các kỹ thuật phát hiện biến động sử dụng đất và che phủ được sử dụng rộng rãi để đánh giá các mô hình tăng trưởng đô thị và ảnh hưởng của nó đối với chuyển động năng động của việc sử dụng đất. Các nghiên cứu quốc tế áp dụng các kỹ thuật này chủ yếu nhằm xác định những thay đổi có liên quan đến vấn đề trong khi bỏ qua những thay đồi không quan trọng (Hardin et al., 2007), các phương pháp và thuật toán định lượng và định tính như lớp phủ hình ảnh (Hardin et al., 2007), chênh lệch hình ảnh (Maktav \& Erbek, 2005), cây quyết định (Wei et al., 2012), so sánh sau phân loại (Madhavan et al., 2001), và mạng nơ-ron (Pajares et al., 2007) được sử dụng để theo dõi những thay đổi của đô thị. Các ứng dụng viễn thám và GIS trong nước cũng được áp dụng rộng rãi trong nhiều lĩnh vực khác nhau đặc biệt trong việc theo dõi, quản lý và đánh giá sự phát triển của đô thị đã được nhiều nghiên cứu chứng minh là công cụ hiệu quả trong việc giám sát và phân tích quá trình đô thị hóa (Huỳnh Trọng Nhân, 2021; Lê Văn Trung và ctv., 2018; Trần Thị Vân và ctv., 2008).

Bài báo này cung cấp một cái nhìn tổng quan về các kỹ thuật chính được sử dụng để đánh giá và đo lường tốc độ tăng trưởng đô thị cũng như các phương pháp phát hiện biển động sử dụng đất như một mô hình quan trọng trong các nghiên cứu sử dụng đất nhằm tìm ra xu hướng phát triển đô thị của TP. Cần Thơ phục vụ cho quy hoạch, nâng cấp, mở rộng, phát triển thành phố đô thị năng động, một đô thị trung tâm kinh tế ở vùng ĐBCSL trong tương lai. 


\section{TỔNG QUAN KHU VỰC NGHIÊN CÚU}

TP. Cần Thơ nằm ở trung tâm vùng ĐBSCL, trải dài trên $65 \mathrm{~km}$ dọc bờ Tây sông Hậu với diện tích tự nhiên $1.401 \mathrm{~km}^{2}$, trải dài từ $105^{\circ} 13^{\prime} 38^{\prime \prime}$ 105 $50^{\prime} 35^{\prime \prime}$ kinh độ Đông và từ $9^{\circ} 55^{\prime} 08^{\prime \prime}$ $10^{\circ} 19^{\prime} 38^{\prime \prime}$ vĩ độ Bắc. Phía Bắc của thành phố giáp với tỉnh An Giang; phía Đông giáp với tỉnh Đồng Tháp, Vĩnh Long; phía Tây giáp với tỉnh Kiên Giang; phía Nam giáp với tỉnh Hậu Giang. Cần Thơ có 9 đơn vị hành chính bao gồm 5 quận (Ninh Kiều, Bình Thủy, Cái Răng, Ô Môn, Thốt Nốt) và 4 huyện (Vĩnh Thạnh, Cờ Đỏ, Thới Lai, Phong Điền) (Cổng thông tin điện tử Thành phố Cần Thơ, 2017) (Hình 1).

Trong 10 năm từ 2009 - 2019, quá trình đô thị hóa diễn ra nhanh và rộng khắp, cũng như nhiều địa phương trong khu vực ĐBSCL, dân số TP. Cần Thơ có sự dịch chuyển từ nông thôn về thành thị và từ miền Tây Nam Bộ về miền Đông Nam Bộ. Ở giai đoạn 2009 - 2019, dân số khu vực thành thị tăng 77.271 người, trong khi đó dân số ở khu vực nông thôn giảm 30.535 người. Điều này cho thấy tiến trình đô thị hóa ở TP. Cần Thơ diê̂n ra nhanh hơn ở cấp độ vùng và toàn quốc. Qua kết quả điều tra dân số TP. Cần Thơ tổng số 1.235.171 người, trong đó tập trung ở khu vực thành thị là 860.557 người, chiếm 69,67\%; nông thôn chiếm 30,33\%. Quận Ninh Kiều đông dân nhất với 280.494 người và huyện Vĩnh Thạnh có dân số ít nhất là 98.399 người. TP. Cần Thơ có mật độ dân số 858 người $/ \mathrm{km}^{2}$, cao gấp 3 lần mật độ dân số toàn quốc và đứng thứ 12/63 tỉnh, thành cả nước (Tổng cục Thống kê, 2020).

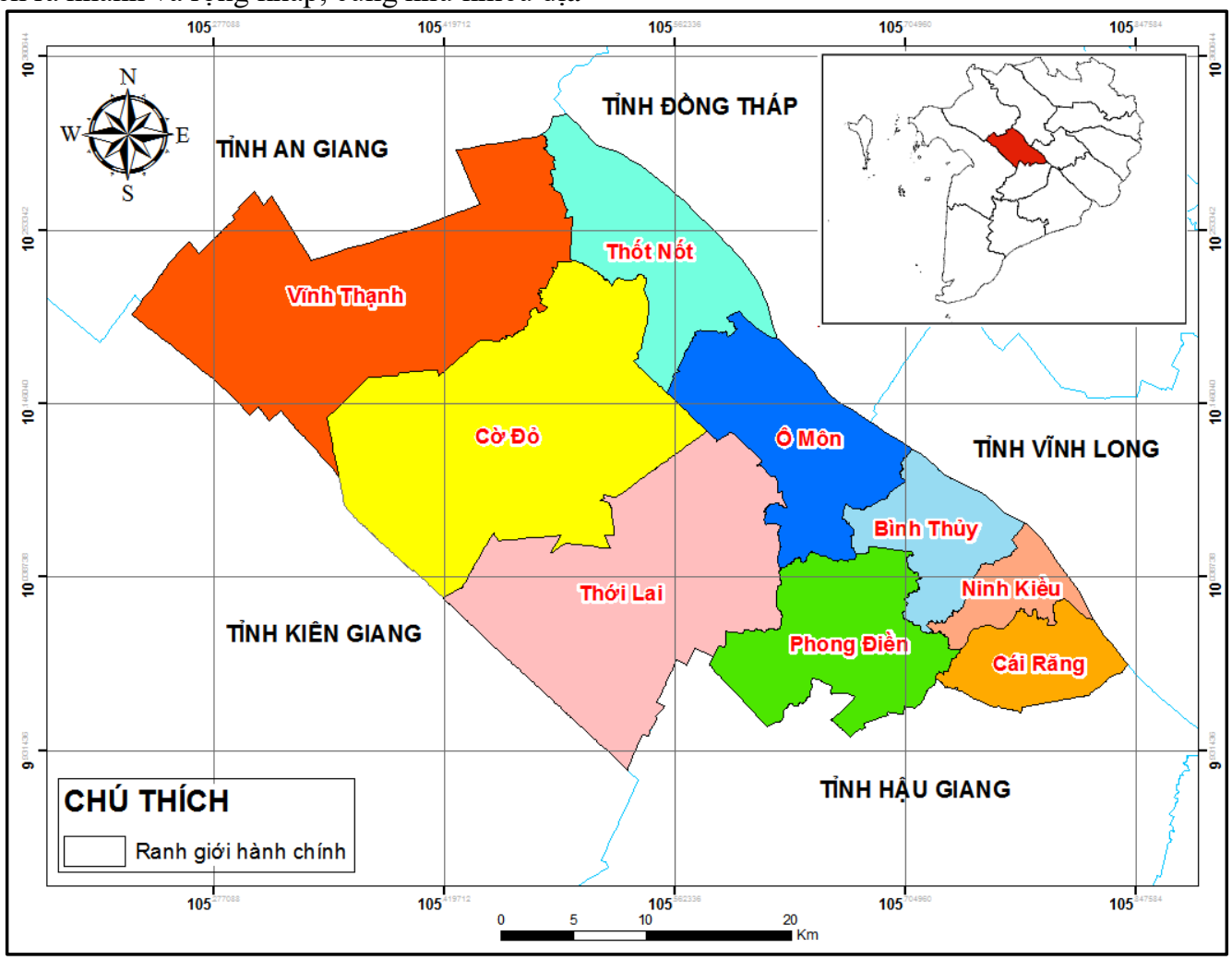

Hình 1. Bản đồ hành chính TP. Cần Tho

\section{PHƯƠNG PHÁP NGHIÊN CÚU}

\subsection{Thu thập dữ liệu}

Ảnh viễn thám Landsat $5(\mathrm{TM})$ được thu thập vào ngày $24 / 8 / 2004$, mây phủ $1,0 \%$ và ảnh Landsat 8 (OLI) thu vào ngày $21 / 12 / 2019$, mây phủ $2,17 \%$ bao phủ khu vực nghiên cứu. Các ảnh Landsat được tải từ địa chỉ website https://earthexplorer.usgs.gov/ của Cục Khảo sát địa chất Hoa kỳ (USGS) với độ phân giải $30 \mathrm{~m}$, hệ quy chiếu UTM, Zone 48 North (Hình 2). 


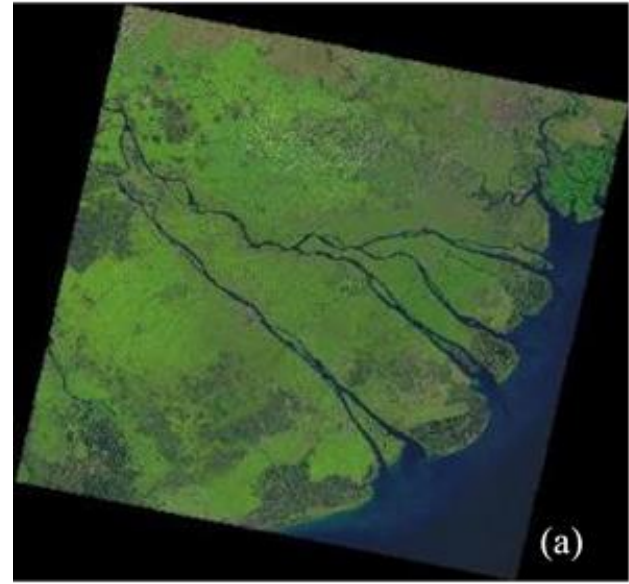

Hình 2. Ảnh LANDSAT 8 - OLI 2019 (a) và ảnh LANDSAT 5 - TM 2004 (b)

Thu thập các bản đồ: Bản đồ hành chính và bản đồ quy hoạch sử dụng đất TP. Cần Thơ được cung cấp từ Sở Tài nguyên và Môi trường $\mathrm{TP}$. Cần Thơ (2019).

Thu thập số liệu, tài liệu: Số liệu thống kê về tình hình đô thị, mật độ đô thị và dân số (Cục Thống kê TP. Cần Thơ, 2019.

\subsection{Xử lý và phân loại ảnh viễn thám}

\subsubsection{Hiệu chinh khi quyển}

- Hiệu chinh bức xạ: Đối với bộ dữ liệu Landsat cấp độ 1 (level-1), các giá trị được chuẩn hóa dưới dạng số nguyên $(\mathrm{DN})$. Các giá trị này được chuyển đổi sang giá trị bức xạ phổ làm dữ liệu đầu vào cho quy trình hiệu chỉnh khí quyển. Việc hiệu chỉnh dựa vào các giá trị riêng biệt của từng bộ cảm biến. Nghiên cứu thực hiện dựa trên công thức (1) như sau (Cục Khảo sát Địa chất Hoa kỳ, 2013):

$$
\mathrm{L} \lambda=\mathrm{ML}^{*} \mathrm{Qcal}+\mathrm{AL} \quad(1)
$$

Trong đó: $\mathrm{L} \lambda$ là giá trị bức xạ của mỗi pixel trên ảnh (Radiance Value), ML là giá trị RADIANCE_MULT_BAND_n trong tập tin metadata. $\mathrm{AL}$ là giá trị, RADIANCE_ADD_BAND_n trong tập tin metadata. Qcal là giá trị $\mathrm{DN}$ của pixel.

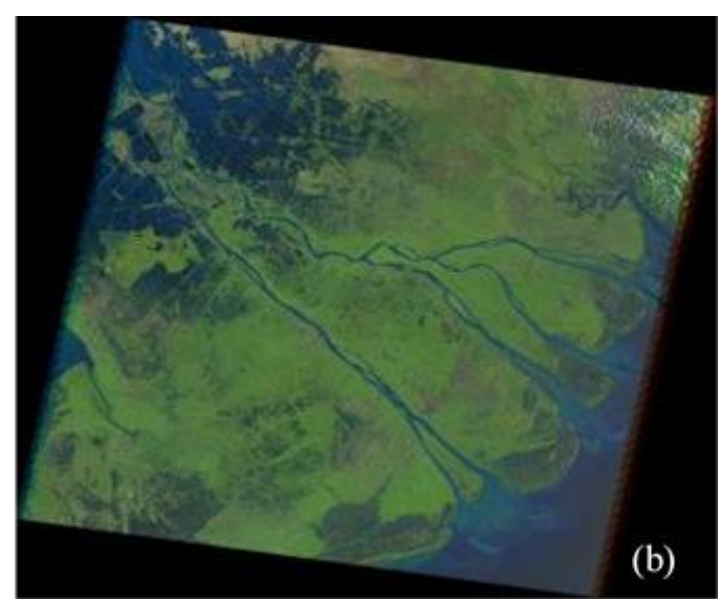

- Hiệu chỉnh khi quyển: Nhằm loại bỏ những ảnh hưởng của khí quyển đến dữ liệu ảnh và tạo ra giá trị phản xa thực tế từ mặt đất (Reflectance value), phương pháp FLAASH trên phần mềm ENVI 5.2 được áp dụng.

\subsubsection{Tính toán các chỉ số phổ}

Các ảnh chỉ số thực vật (Normalized difference vegetation index - NDVI), ảnh chỉ số đất xây dựng (Normal Difference Built-up Index - NDBI và ảnh chỉ số nước (Normal Difference Water Index NDWI) được tính toán để làm cơ sở giải đoán ảnh Landsat trong phân loại xây dựng bản đồ hiện trạng sử dụng đất của TP. Cần Thơ. Trong đó, chỉ số chuẩn hóa khác biệt thực vật (NDVI) là một thuật toán tiêu chuẩn được thiết kế để ước tính chất lượng thảm thực vật dựa trên màu xanh lá cây trên mặt đất bằng phép đo phản xạ ở bước sóng màu đỏ và cận hồng ngoại (Tucker, 1979). Chỉ số chuẩn hóa khác biệt về bề mặt đất xây dựng (NDBI) được phát triển bởi Zha et al. (2003) để giúp nhận diện đô thị trên ảnh. Chỉ số chuẩn hóa khác biệt nước (NDWI) được phát triển bởi Gao (1996) là chỉ số giúp phân tách đối tượng nước khỏi các đối tượng thực phủ (Bảng 1).

\section{Bảng 1. Công thức tính toán các chỉ số}

\begin{tabular}{lrl}
\hline Chỉ số & Công thức & Tác giả \\
\hline Chỉ số chuẩn hóa khác biệt về thực vật NDVI & $N D V I=\frac{(\mathrm{NIR}-\mathrm{RED})}{(\mathrm{NIR}+\mathrm{RED})}$ & Tucker (1979) \\
\hline Chỉ số chuẩn hóa khác biệt về bề mặt đất xây dựng NDBI & $N D B I=\frac{(\mathrm{SWIR}-\mathrm{NIR})}{(\mathrm{SWIR}+\mathrm{NIR})}$ & Zha et al. (2003) \\
\cline { 1 - 2 } Chỉ số chuẩn hóa khác biệt về nước NDWI & $N D W I=\frac{(\mathrm{NIR}-\mathrm{SWIR})}{(\mathrm{NIR}+\mathrm{SWIR})}$ & \\
\hline
\end{tabular}




\subsubsection{Phân loại ảnh bằng thuật toán có kiểm dịnh}

Ảnh Landsat được phân loại bằng phương pháp giám định bằng thuật toán xác suất gần đúng (Maximum Likelihood Classifier) từ các ảnh chỉ số để phân biệt các loại lớp phủ mặt đất gồm đất đô thị, đất trồng lúa, đất cây lâu năm và sông ngòi, kênh rạch vào thời điểm năm 2004 và năm 2019.

Các bản đồ sau khi phân loại được vector hóa để thành lập bản đồ lớp phủ mặt đất tại mỗi thời điểm; sau đó, phân tích biến động các loại lớp phủ mặt đất bằng cách chồng lớp các bản đồ giai đoạn 2014 2019 bằng thuật toán Union trên phần mền ArcGIS.

\subsubsection{Kiểm định sau phân loại}

Điểm mẫu (198) phân bố ngẫu nhiên mỗi năm 2004 và 2019 được thu thập từ phần mềm Google Earth bằng chức năng Show historical imagery để tiến hành kiểm tra độ tin cậy (Hu et al. 2013). Số lượng mẫu phân bố được trình bày trên Bảng 2 , trong đó phân bố các điểm trên hiện trạng cây lâu năm, đô thị và lúa chiếm tỉ lệ từ $31,31 \%$ đến $35,86 \%$ năm 2004 và phân bố cao nhất trên đất đô thị chiếm 40,40\% năm 2019. Các điểm đô thị được phân bố trên khu vực đô thị tập trung chủ yếu tại 3 quận trung tâm gồm Ninh Kiều, Bình Thủy và Cái Răng. Các điểm không đô thị được đánh dấu ngẫu nhiên trên các hiện trạng khác như cây lâu năm, ruộng lúa trên khu vực nghiên cứu.

Bảng 2. Số lượng điểm khảo sát trên hiện trạng

\begin{tabular}{lrrrr}
\hline \multirow{2}{*}{$\begin{array}{l}\text { Hiện } \\
\text { trạng }\end{array}$} & \multicolumn{2}{c}{ Năm 2004 } & \multicolumn{2}{c}{ Năm 2019 } \\
\cline { 2 - 5 } & $\begin{array}{r}\text { Điểm } \\
\text { khảo sát }\end{array}$ & $\begin{array}{r}\text { Tỷ lệ } \\
(\mathbf{\%})\end{array}$ & $\begin{array}{r}\text { Điểm } \\
\text { khảo sát }\end{array}$ & $\begin{array}{r}\text { Tỷ lệ } \\
(\mathbf{\%})\end{array}$ \\
\hline CLN & 71 & 35,86 & 50 & 25,25 \\
Đô thị & 60 & 30,30 & 80 & 40,40 \\
Sông & 5 & 2,53 & - & - \\
Lúa & 62 & 31,31 & 68 & 34,34 \\
\hline Tổng & 198 & 100 & 198 & 100 \\
\hline
\end{tabular}

Sử dụng hai chỉ số là độ chính xác toàn cục $(\mathrm{T})$ và chỉ số Kappa $(\mathrm{K})$ nhằm thống kê, kiểm tra và đánh giá sự phù hợp giữa dữ liệu và dữ liệu thực tế được đại diện bằng các điểm mẫu.

\subsection{Phân tích tình hình phát triển đô thị}

\subsubsection{Tính mật độ đô thị}

Sự phát triển đô thị được đánh giá dựa trên mật độ đô thị. Mật độ đô thị thể hiện sự tập trung và là tiêu chí giúp đánh giá giữa các quận, huyện về mức độ phát triển đô thị. Mật độ đô thị được định nghĩa là thương số giữa diện tích đô thị so với tổng diện tích đất tự nhiên (Ahmad \& Goparaju, 2016).

$$
\mathrm{MD}=\frac{\mathrm{S}_{\mathrm{DT}}}{\mathrm{S}_{\mathrm{TN}}} \times 100 \%
$$

Trong đó: $\mathrm{MD}(\%)$ là mật độ đô thị, $\mathrm{S}_{\mathrm{DT}}(\mathrm{ha})$ là diện tích đô thị, $\mathrm{S}_{\mathrm{TN}}(\mathrm{ha})$ là diện tích đất tự nhiên.

\subsubsection{Tính tốc độ đô thị hóa trung bình năm}

Đô thị hóa còn được đánh giá bằng tốc độ đô thị hóa trung bình năm, đây là tỷ lệ giữa diện tích đô thị tăng thêm và tổng diện tích tự nhiên sau thời gian tăng trưởng (Ahmad \& Goparaju, 2016).

$$
\mathrm{TD}=\frac{S_{D T_{j}} S_{D T_{i}}}{(j-i) S_{T N}} \times 100 \%
$$

Trong đó, TD là tốc độ đô thị hóa trung bình năm (\%/năm), $\mathrm{S}_{\mathrm{DT} i}$ và $\mathrm{S}_{\mathrm{DTj}}$ lần lượt là diện tích đô thị ở năm đầu kỳ và cuối kỳ (ha), (j-i) là giai đoạn ước tính tốc độ đô thị hóa (năm), $\mathrm{S}_{\mathrm{TN}}$ (ha) là tổng diện tích tự nhiên.

\subsubsection{Phân tích điểm nóng (Hot Spot Analysis - Getis-Ord $\mathrm{Gi}^{*}$ )}

Công cụ phân tích điểm nóng (Hot Spot Analysis) tính toán giá trị thống kê Getis-Ord Gi* cho mỗi đối tượng trong lớp dữ liệu. Kết quả trả về z-scores và $\mathrm{p}$-values cho biết vị trí phân bố các giá trị cao/thấp tương ứng với nóng/lạnh (Hot/Cold). Công cụ này làm việc bằng cách xem xét mỗi đối tượng trong mối quan hệ với các đối tượng lân cận nó. Trong phép phân tích hotspot, giá trị $\mathrm{p}$ (xác suất) và điểm số $\mathrm{z}$ (độ lệch chuẩn) sẽ được ước tính, trong đó các giá trị dương lớn hơn $z$ là các cụm hotspot (điểm nóng), ngược lai các giá trị âm nhỏ hơn $\mathrm{z}$ được phân nhóm là các cụm điểm coldspot (điểm lạnh) (ESRI, 2018).

Trong nghiên cứu này, sự tập trung đô thị được phân tích bằng phương pháp Hot Spot Analysis (Getis-Ord $\mathrm{Gi}^{*}$ ) trên mật độ đô thị của từng ô lục giác có cạnh $1 \mathrm{~km}$. Các thông số được chọn cho phân tích gồm: mật độ đô thị trên từng ô lục giác, quan hệ không gian trong tiêu chí khoảng cách được nêu ở thông số kế tiếp, khoảng cách ngắn nhất (Euclidean distance), khoảng cách có quan hệ giữa các ô lục giác liền kề với lục giác cần xét (cạnh lục giác 1.000 $\mathrm{m})$.

\subsubsection{Phân tích khoảng cách ngắn nhất (Euclidean distance)}

Khoảng cách ngắn nhất đến đối tượng được tính toán cho mỗi pixel, do đó dữ liệu đầu vào được chuyển đổi sang dạng raster khi tính khoảng cách Euclid. Khoảng cách Euclid được tính từ tâm của 
các pixel đối tượng đến các pixel xung quanh. Trong nghiên cứu này, khoảng cách ngắn nhất được tính bằng công cụ Euclidean distance trong ArcGIS cho đối tượng từ trung tâm đô thị.

\section{KẾT QUẢ NGHIÊN CÚU}

\section{1. Đánh giá độ tin cậy ảnh sau phân loại}

Bảng 3 cho thấy kết quả phân loại hiện trạng đô thị cả hai năm 2004 và 2019 đều đạt độ tin cậy rất tốt với độ chính xác toàn cục đạt trên $90 \%$ và hệ số Kappa > 0,85. Cụ thể, kết quả phân loại năm 2004 đạt độ chính xác toàn cục và hệ số Kappa lần lượt là $94,5 \%$ và 0,89 và năm 2019 là $96,5 \%$ và 0,93 .

Kết quả ước tính độ tin cậy sử dụng độ chính xác toàn cục $(\mathrm{T})$ và hệ số Kappa $(\mathrm{K})$ cho thấy kết quả giải đoán ảnh sau phân loại có độ tin cậy khá cao, sai số khoảng 7-11\% so với thực tể và mức độ nhầm lẫn của các đối tượng hiện trạng được phân loại khoảng 3,5 - 5,5\%.

\section{Bảng 3. Kết quả đánh giá độ tin cậy phân loại}

\begin{tabular}{|c|c|c|}
\hline Năm & $\begin{array}{r}\text { Độ chính xác toàn cục } \\
(\%)\end{array}$ & $\begin{array}{r}\text { Chỉ số } \\
\text { Kappa }\end{array}$ \\
\hline 2004 & 94,5 & 0,89 \\
\hline 2019 & 96,5 & 0,93 \\
\hline
\end{tabular}

\subsection{Hiện trạng sử dụng thành phố Cần Tho}

Việc xây dựng bản đồ hiện trạng sử dụng đất dựa trên cơ sở phân loại ảnh viễn thám và sử dụng kết quả phân loại ảnh để phân tích xu hướng phát triển đô thị hóa TP. Cần Thơ. Bản đồ hiện trạng thực phủ được phân loại thành 4 nhóm đối tượng gồm: đất phi nông nghiệp (đất đô thị), đất trồng lúa, đất cây lâu năm và sông rạch (Hình 3 ). Hiện trạng đất phi nông nghiệp được hiểu trong nghiên cứu là đất thổ cư hay vùng đất đô thị.

Giai đoạn 2004-2019, phân bố không gian các kiểu hiện trạng tại TP. Cần Thơ được chia thành 3 vùng chính: vùng tập trung đất phi nông nghiệp (đất thổ cư) dọc theo bờ sông Hậu tại các quận trung tâm gồm Ninh Kiều, Bình Thủy, Thốt Nốt; vùng tập trung đất trồng lúa tại các huyện gồm Vĩnh Thạnh, Cờ Đỏ và Thới Lai và vùng phân bố chủ yếu của cây lâu năm/cây ăn trái tại quận/huyện Phong Điền, Cái Răng và Ô Môn. Đến năm 2019, vùng tập trung đô thị tiếp tục mở rộng theo hướng dọc theo sông Hậu và lan tỏa theo các tuyến đường chính, ngoài ra một phần đô thị có xu hướng mở rộng về phía Quận Cái Răng (Hình 3).

Năm 2004, 2 loại hiện trạng sử dụng đất gồm đất trồng lúa và cây lâu năm chiểm diện tích cao nhất lần lượt là $78.337,3$ ha và $52.707,2$ ha với tỉ lệ khoảng $54,42 \%$ và $36,61 \%$ tổng diện tích tự nhiên và thấp nhất là đất xây dựng đô thị với $6.400,2$ ha chiếm 4,45\% (Hình 3).

Năm 2019, tỉ lệ các kiểu thực phủ có sự thay đổi như sau: đất trồng lúa và cây lâu năm vẫn chiếm tỉ lệ cao nhất với diện tích và tỉ lệ lần lượt là $91.526,6$ ha $(63,57 \%)$ và $30.478,4$ ha $(21,17 \%)$, trong đó đất trồng lúa có khuynh hướng tăng và đất trồng cây lâu năm có khuynh hướng giảm so với năm 2004. Diện tích đất xây dựng đô thị năm 2019 tăng lên 16.007,0 ha chiếm $11,12 \%$ diện tích tự nhiên toàn khu vực, tăng gần gấp 3 lần so với năm 2004 (Hình 3).

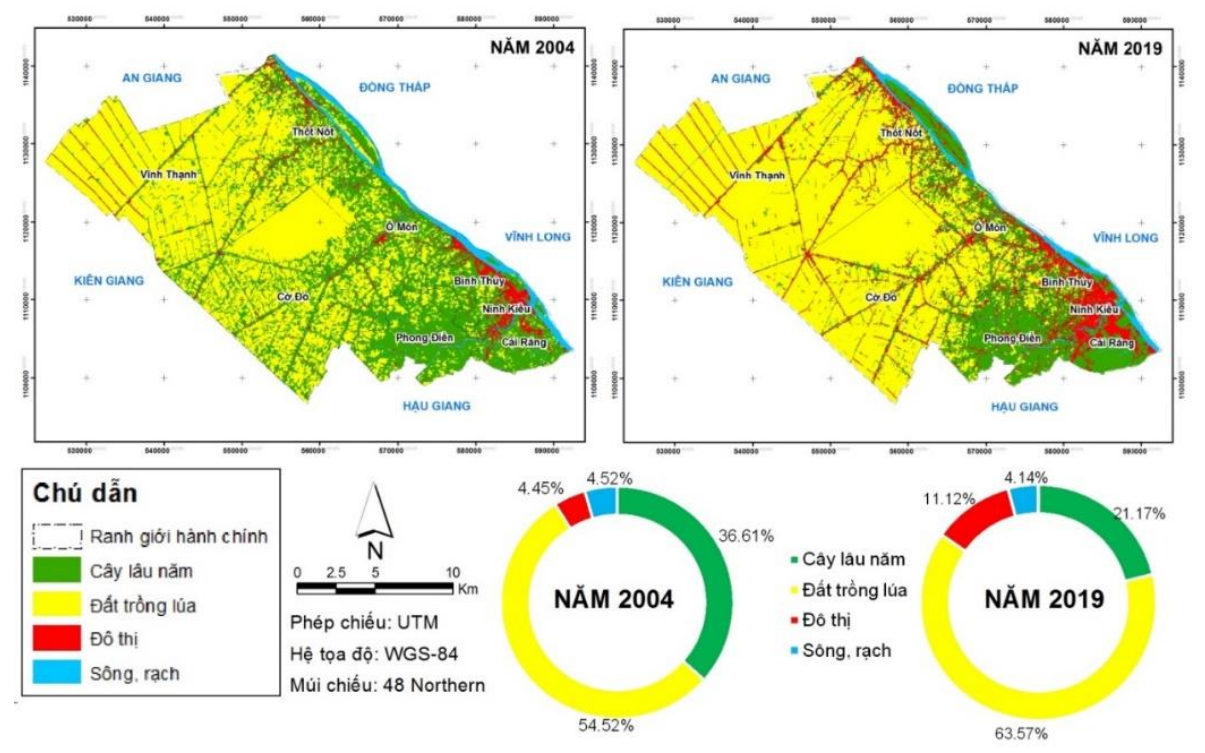

Hình 3. Bản đồ hiện trạng sử dụng đất TP. Cần Thơ năm 2004 và năm 2019 


\subsection{Tình hình phát triển đô thị TP. Cần Thơ giai doạn 2004 - 2019}

\subsubsection{Sự thay đổi về diện tích đô thị}

Theo kết quả phân loại hiện trạng, diện tích đô thị năm 2004 từng quận, huyện, trong đó thấp nhất tại huyện Phong Điền với 156,5 ha (chiếm 2,4\% tổng diện tích đô thị), quận có diện tích đô thị cao nhất trong giai đoạn này là Ninh Kiều với 1.204,9 ha (chiếm 19,4\%). Đến năm 2019, huyện Phong Điền vẫn là huyện có diện tích đô thị thấp nhất so với các quận, huyện khác chiếm khoảng 7,0\% tổng diện tích đô thị toàn thành phố (1.117,6 ha). Quận
Ninh Kiều không còn là quận có diện tích đô thị lớn nhất thay vào đó là quận Bình Thủy đã phát triển nhiều hơn chiếm $13,1 \%$ diện tích đô thị toàn thành phố với 2.098,8 ha. Nhìn chung, giai đoạn 20042019, diện tích đô thị tại TP. Cần Thơ tăng khoảng 9.606,0 ha (tăng 150,09\% so với diện tích đô thị năm 2004). Quận Ninh Kiều có tỉ lệ diện tích đô thị tăng ít nhất với 658,4 ha (tăng 53,06\%) so với diện tích đô thị năm 2004. Huyện Phong Điền có tỉ lệ biến động cao nhất với 1.117,6 ha (614,12\%). Các quận, huyện còn lại có tỉ lệ biến động dao động trong khoảng từ 114,21\% đến 259,97\% (Bảng 4).

\section{Bảng 4. Biến động diện tích đô thị các quận huyện tại TP. Cần Tho}

\begin{tabular}{lrrrc}
\hline Quận/Huyện & Năm 2004 (ha) & Năm 2019 (ha) & Biến động (ha) & Tỷ lệ biến động (\%) \\
\hline Phong Điền & 156,5 & $1.117,6$ & $+961,10$ & $614,12 \%$ \\
Cờ Đỏ & 504,3 & $1.437,0$ & $+932,70$ & $184,95 \%$ \\
Thới Lai & 508,4 & $1.830,1$ & $+1.321,70$ & $259,97 \%$ \\
Ô Môn & 544,0 & $1.874,0$ & $+1.330,00$ & $244,49 \%$ \\
Cái Răng & 681,9 & $1.728,0$ & $+1.046,10$ & $153,41 \%$ \\
Vĩnh Thạnh & 880,0 & $1.973,8$ & $+1.093,80$ & $124,30 \%$ \\
Thốt Nốt & 904,4 & $2.048,4$ & $+1.144,00$ & $126,49 \%$ \\
Bình Thủy & 979,8 & $2.098,8$ & $+1.119,00$ & $114,21 \%$ \\
Ninh Kiều & $1.240,9$ & $1.899,3$ & $+658,40$ & $53,06 \%$ \\
\hline Tổng & $6.400,2$ & $16.007,0$ & $+9.606,0$ & $150,09 \%$ \\
\hline
\end{tabular}

4.3.2. Sự thay đổi mật độ đô thị TP. Cần Tho giai đoạn 2004 - 2019

TP. Cần Thơ được tách từ tỉnh Hậu Giang vào năm 2003, vào thời điểm này phần lớn các quận, huyện đều có tỉ lệ phần trăm (\%) mật độ đô thị thấp hơn $15 \%$, chỉ riêng quận Ninh Kiều là trung tâm phát triển nên mật độ đô thị khá dày với $42,9 \%$. Bên cạnh đó, các ngoại thành lân cận gồm quận Bình Thủy và quận Cái Răng tuy mật độ đô thị thấp nhưng vẫn cao hơn so với các quận khác với $\%$ mật độ đô thị lần lượt là $14,0 \%$ và $10,2 \%$. Ngược lại, các huyện nông thôn như Vĩnh Thạnh, Phong Điền, Cờ Đỏ và Thới Lai có phân bố mật độ đô thị thấp hơn $3 \%$ với giá trị cụ thể lần lượt là $2,94 \%, 1,26 \%, 1,58 \%$ và
1,91\% (Hình 5). Đến năm 2019, quận Ninh Kiều trung tâm của thành phố có mật độ đô thị phát triển rất nhanh với khoảng $65,6 \%$ diện tích toàn quận. Hai quận lân cận gồm Bình Thủy và Cái Răng cũng có sự phát triển đô thị đáng kể với mật độ lần lượt là $29,9 \%$ và $25,86 \%$. Bốn huyện có mật độ đô thị thấp nhất năm 2004 gồm Phong Điền, Thới Lai, Vĩnh Thạnh và Cờ Đỏ thì tiếp tục mật độ đô thị có phát triển nhưng vẫn thấp nhất dưới $10 \%$ trong toàn thành phố Cần thơ phân bố lần lượt là $9 \%, \&, 8 \%, 6,6 \%$ và $4,5 \%$ do các huyện này vẫn còn duy trì thế mạnh phát triển sản xuất nông nghiệp trong đó huyện Cờ Đỏ có mật độ dân số thấp nhất chỉ tăng từ $1,58-$ 4,5\% giai đoạn $2004-2019$. 


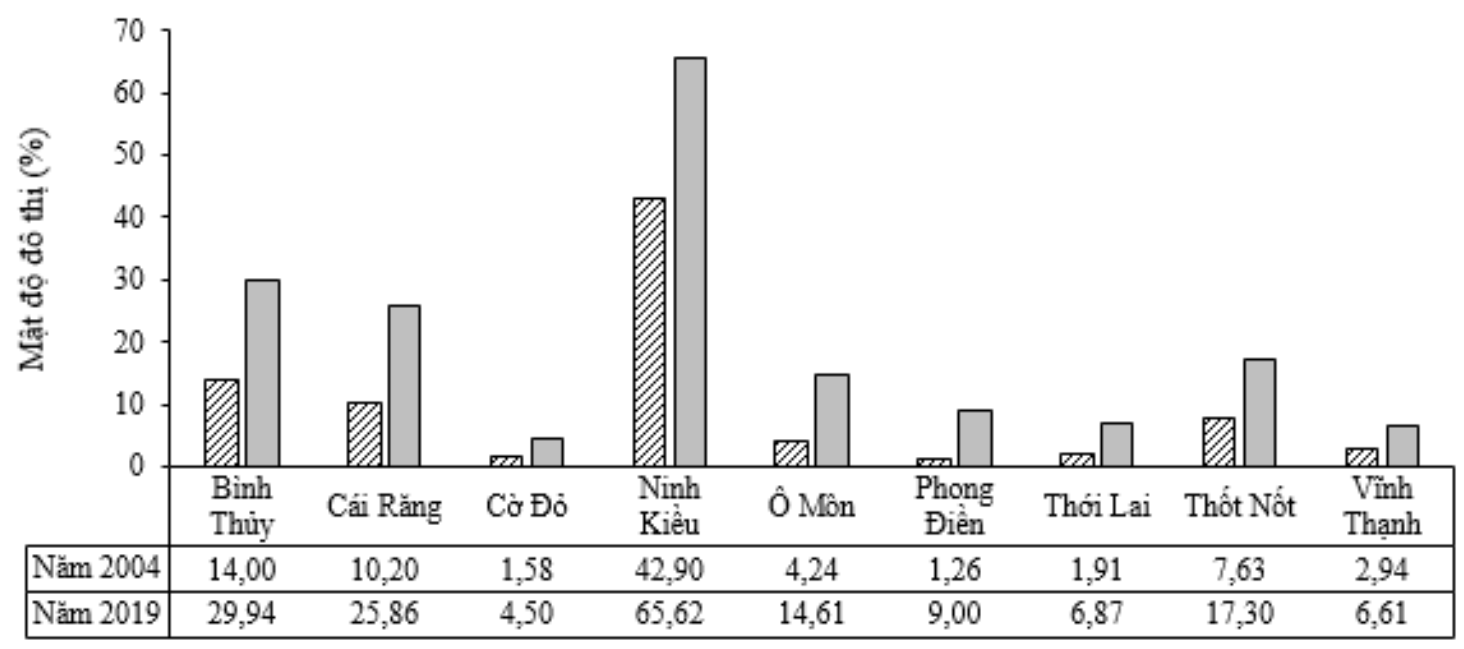

๒Năm 2004 口Năm 2019

\section{Hình 4. Biểu đồ phân bố mật độ đô thị TP. Cần Thơ giai đoạn 2004- 2019}

4.3.3. Phân tích mức độ tập trung đô thị (phân tích điểm nóng Hotspot)

Theo phân tích Hotspot năm 2004, các điểm nóng trên bản đồ với mức ý nghĩa $\mathrm{p} \geq 90 \%$ thể hiện sự tập trung cao đô thị, phân bố chủ yếu ở quận Ninh Kiều, phía Tây Bắc quận Cái Răng và quận Bình Thủy tuyến dọc sông Hậu và vùng tập trung đô thị ở trung tâm quận Thốt Nốt (Hình 5a).

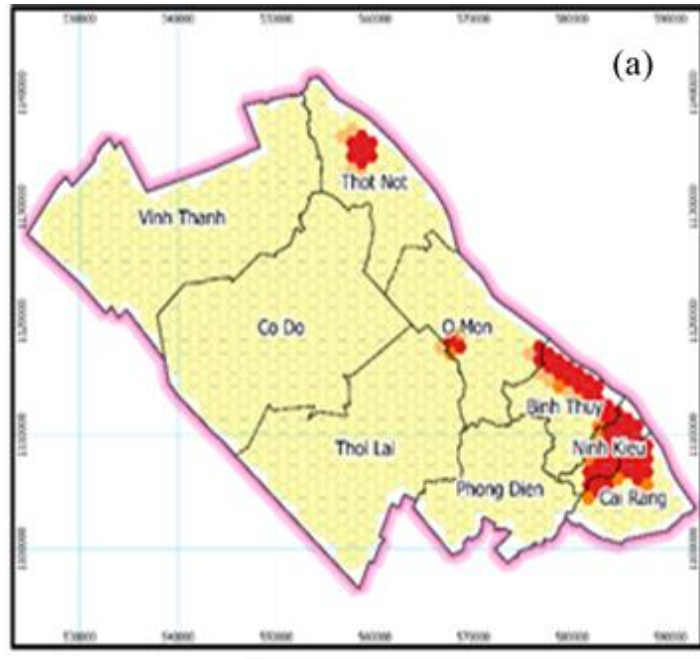

\section{CHÚ DÃN}

Ranh giới hành chính Tính

Ranh giới hành chính quận, huyện

Mức ý nghĩa

Không khác biêt ý nghia

Hotspot - Mức đồ ý nghia 90\%

Hotspot - Mức đô ý nghia 95\%

Hotspot - Mức đô ý nghia 99\%

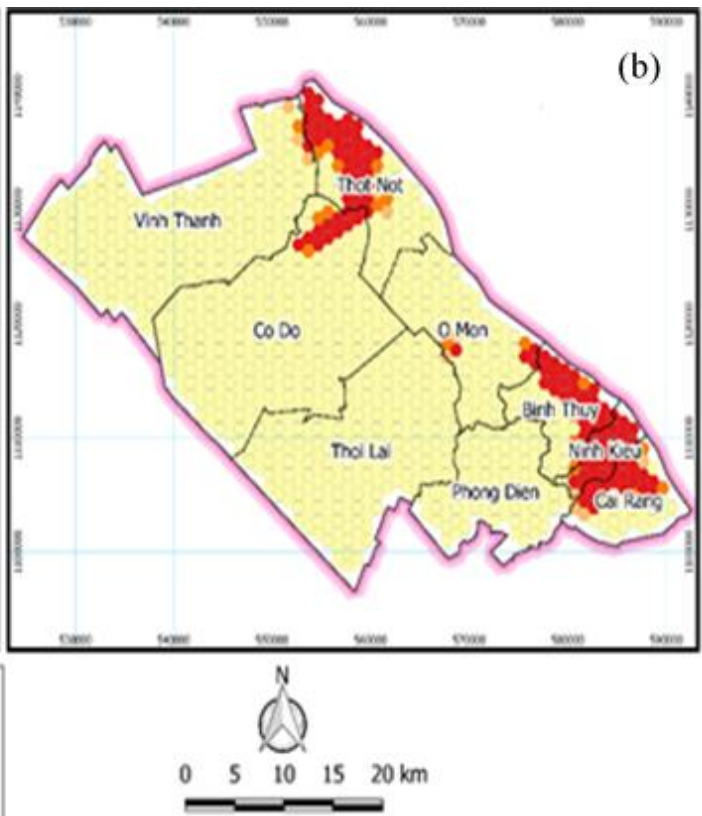

Phép chiễu: UTM

Hệ tọa độ: WGS-84

Múi chiễu: 48 Northern

Hình 5. Bản đồ mức độ tập trung đô thị ở TP. Cần Thơ năm 2004 (a) và năm 2019 (b) 
Năm 2019, xu hướng tập trung đô thị trên địa bàn thành phố dường như không thay đổi, tuy nhiên có sự phát triển về không gian đáng kể. Vùng tập trung đô thị tại trung tâm thành phố ở các quận Ninh Kiều, Bình Thủy và Cái Răng đã mở rộng phạm vi đô thị theo hướng Đông Nam dọc theo các tuyến quốc lộ. Quận Cái Răng có sự mở rộng đô thị rất nhanh theo hướng các tuyến quốc lộ chính, quận Bình Thủy có sự phát triển mở rộng về hướng đi Ồ Môn (Hình $5 b$ ).

\subsubsection{Phát triển không gian đô thị}

Thay đổi không gian đô thị giai đoạn 2004-2019 được thể hiện qua Hình 6 , trong đó vùng đô thị chính năm 2004 tập trung chủ yếu ở trung tâm quận Ninh Kiều, dọc theo tuyến sông Hậu ở các quận Bình Thủy, Thốt Nốt và tại trung tâm của các quận, huyện còn lại. Đến năm 2019, không gian đô thị có sự thay đổi đáng kể, chủ yếu mở rộng từ các vùng đô thị trước đây và theo các tuyến đường giao thông chính. Tình hình đô thị hóa giai đoạn 2004 - 2019 phát triển mạnh ở 2 hướng chính: thứ nhất là hướng dọc theo sông Hậu, hình thành một đô thị dạng chuỗi; thứ hai là hướng theo sông Cần Thơ về phía Nam. Các quận, huyện bắt đầu kết nối lại với nhau hình thành một chuồi liên tiếp gồm các quận Cái Răng, Ninh Kiều,

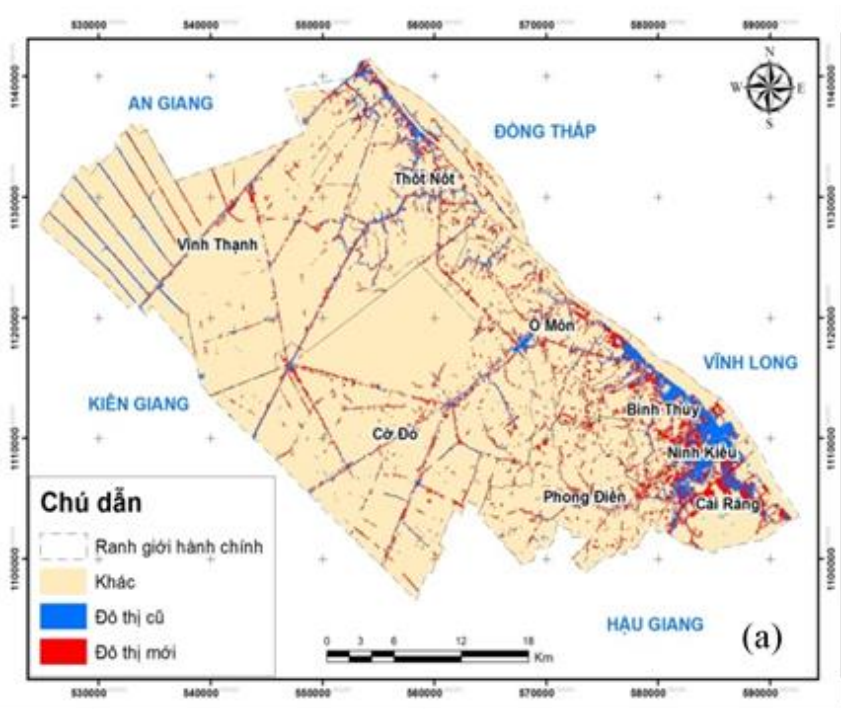

Bình Thuỷ, Ô Môn, Thốt Nốt. Quận Cái Răng có sự mở rộng đô thị rất cao theo hướng các tuyến quốc lộ chính, quận Bình Thủy có sự phát triển mở rộng về hướng đi Ô Môn.

Kết quả phát triển không gian đô thị tương đối phù hợp theo định hướng quy hoạch chung của TP. Cần Thơ phát triển kinh tế xã hội được phê duyệt năm 2013, gồm phát triển các khu đô thị nội thành là Ninh Kiều và Bình Thủy, các khu đô thị - công nghiệp Trà Nóc, Cái Răng và Thốt Nốt, khu đô thị sinh thái Phong Điền, khu đô thị mới Ô Môn. Khu vực ngoại thành gồm thị trấn các huyện Cờ Đỏ, Thới Lai, Vĩnh Thạnh và Thanh An. Đồng thời, các dự án chỉnh trang triển khai đầu tư xây dựng, nâng cấp các tuyến giao thông trên địa bàn thành phố như các tuyến quốc lộ 91, quốc lộ 91B, quốc lộ 80, Nam sông Hậu; đường Võ Văn Kiệt, Nguyễn Văn Cừ, Quang Trung - Cái Cui, cầu Quang Trung, đường Trần Hoàng Na phục vụ phát triển kinh tế - xã hội của thành phố. Hơn nữa, tập quán người dân vùng ĐBSCL thường sinh sống ven sông và dọc các tuyến quốc lộ được chỉnh trang và xây dựng mới cũng góp phần vào phát triển không gian đồ thị giai đoạn này (Ủy ban nhân dân thành phố Cần Thơ, 2013).

\section{Hình 6. Bản đồ (a) và biểu đồ (b) tốc độ đô thị hóa TP. Cần Thơ giai đoạn 2004 - 2019}

Trong giai đoạn 2004-2019, nghiên cứu cũng tìm thấy xu hướng tăng trưởng đô thị cao nhất tại quận Ninh Kiều với tốc độ đô thị hóa trung bình năm đạt $1,52 \% /$ năm. Tiếp đến quận Bình Thủy và Cái Răng cũng có tốc độ phát triển đáng kể với $1,06 \% /$ năm và $1,04 \% /$ năm do được thừa hưởng những lợi thế phát triển từ quận Ninh Kiều. Các quận có truyền thống canh tác nông nghiệp như huyện Cờ Đỏ, Vĩnh Thạnh và Thới Lai có mức tăng trưởng đô thị trung bình năm chỉ đạt dưới $0,35 \% /$ năm.

Theo số liệu thống kê tình hình phát triển đô thị (2020), tốc độ đô thị hóa cả nước giai đoạn 20152020 lả 3,1\%/năm với tỉ lệ đô thị hóa bình quân trên $1 \% /$ năm, riêng Hà Nội, TP.Hồ Chí Minh đạt trên $3 \% /$ năm, trong khi đó TP. Cần Thơ có tốc độ đô thị 
hóa $(0,43 \% /$ năm) thấp hơn khoảng 6 lần so với 2 đô thị lớn Hà Nội và thành phố Hồ Chí Minh.

Qua kết quả điều tra của Tổng cục Thống kê (2020), dân số tập trung ở khu vực thành thị là 860.393 người, chiếm $69,66 \%$; nông thôn chiếm $30,34 \%$. TP. Cần Thơ có mật độ dân số 858 người $/ \mathrm{km}^{2}$, cao gấp 3 lần mật độ trung bình dân số toàn quốc và đứng thứ $12 / 63$ tỉnh, thành cả nước. Dân số thành thị TP. Cần Thơ năm 2004 đến 2019 tăng từ 567,3 đến 861,3 ngàn người với tỷ lệ tăng $34,13 \%$ trong vòng 15 năm cho thấy tốc độ tăng dân số vùng đô thị TP. Cần Thơ khá cao, tình hình đô thị hóa đô thị của TP. Cần Thơ tăng trung bình $0,42 \% /$ năm

\section{KẾT LUẬN}

Ảnh LANDSAT được sử dụng để xây dựng bản đồ hiện trạng sử dụng đất và trích lọc phân bố không gian đất đô thị giai đoạn 2004-2019 của TP. Cần Thơ là phù hợp với tỉ lệ cấp tỉnh. Tuy nhiên, hạn chế khi sử dụng ảnh quang học là bị mây che phủ, có thể bổ sung sử dụng ảnh viễ் thám chủ động như ảnh Sentinel 1 trong công tác xây dựng hiện trạng sử đụng đất đặc biệt là hiện trạng đất đô thị.

Kết quả nghiên cứu cho thấy tình hình đô thị hóa tại TP. Cần Thơ còn chậm so với bình quân phát triển đô thị của cả nước, trong khí đó Cần Thơ là trung tâm vùng ĐBSCL, là thành phố đô thị loại 1 trực thuộc Trung ương nên cần có kế hoạch và định phướng phát triển đô thị phù hợp nhằm phát huy tiềm năng kinh tế vùng sông nước và đẩy mạnh phát triển kinh tế xã hội của vùng. Xu hướng đồ thị hóa TP. Cần Thơ phân bố dọc theo tuyến sông Hậu, hình thành một đô thị dạng chuỗi; và dọc theo sông Cần Thơ về phía Tây Nam và theo hướng các tuyến quốc lộ chính phù hợp với định hướng quy hoạch của TP. Cần Thơ đến năm 2020.

Kết quả nghiên cứu là cơ sở hữu ích giúp các nhà quản lý theo dõi biến động và hoạch định các chiến lược phát triển bền vững nhằm cải thiện cuộc sống đô thị, đồng thời cũng hỗ trợ việc xem xét, đánh giá tác động của đô thị hóa lên môi trường sống, sự thay đổi nhiệt độ, tốc độ phát triển đô thị trong bối cảnh đô thị hóa toàn cầu hiện nay.

\section{LỜI CẢM TẠ}

Đề tài được tài trợ bởi Dự án Hợp tác Kỹ thuật "Tăng cường năng lực Trường Đại học Cần Thơ thành trường xuất sắc về đào tạo, nghiên cứu khoa học và chuyển giao công nghệ" của Cơ quan Hợp tác Quốc tế Nhật bản (JICA). Nhóm tác giả chân thành cảm ơn Ban quản lý Dự án Nâng cấp Trường
Đại học Cần Thơ và Chính phủ Nhật Bản đã tài trợ kinh phí thực hiện hoàn thành nghiên cứu này trong đề tài nhánh ODA-E8.

\section{TÀI LIỆU THAM KHẢO}

Ahmad, F., \& Goparaju, L. (2016). Analysis of Urban Sprawl Dynamics Using Geospatial Technology in Ranchi City, Jharkhand, India. J. Environ. Geogr., 9(1-2), 7-13. https://doi.org/10.1515/jengeo-2016-0002.

Aithal, B.H., \& Sanna, D.D. (2012). Insights to urban dynamics through landscape spatial pattern analysis. International Journal of Applied Earth Observation and Geoinformation, 18, 329-343. https://doi.org/10.1016/j.jag.2012.03.005.

Al-shalabi, M., Pradhan, B., Billa, L., Mansor, S., \& Althuwaynee, O.F. (2013). Manifestation of remote sensing data in modeling urban sprawl using the SLEUTH model and brute force calibration: a case study of Sana'a city, Yemen. Journal of the Indian Society of Remote Sensing, 41(2), 405-416. https://doi.org/10.1007/s12524012-0215-6.

Bộ Xây dựng. (2019). Tạp chí Quy hoạch Xây dựng (Số 97+98/2019). https://moc.gov.vn/en/news/52307/quy-hoachtong-the-he-thong-do-thi-quoc-gia--tu-goc-doquan-ly-phat-trien-do-thi.aspx.

Cục khảo sát địa chất Hoa kỳ (USGS). (2019, November 6). USGS Earth Explore. https://earthexplorer.usgs.gov.

Cục Thống kê thành phố Cần Thơ. (2020). Kết quả Tổng điều tra dân số nhà ở năm 2019. Nhà xuất bản Thống kê.

Cục Thống kê thành phố Cần Thơ. (2019). Niên giám thống kê thành phố Cần Tho. Nhà xuất bản Thống kê.

Cổng thông tin điện tử thành phố Cần Thơ (06/12/2017). Tổng quan thành phố Cần Tho: https://www.cantho.gov.vn/wps/portal/home/gioi -thieu/chitiet/Gioi+thieu+TPCT/Gioi+thieu+chung.

ESRI. (2018, October 12). How Hot Spot Analysis (Getis-Ord Gi*) works.

http://desktop.arcgis.com/en/arcmap/10.3/tools/s patial-statistics-toolbox/h-how-hot-spot-analysisgetis-ord-gi-spatial-stati.htm.

Gao, B. C. (1996). NDWI A Normalized Difference Water Index for Remote Sensing of Vegetation Liquid Water from Space. Remote Sensing of Environment, 58(3), 257-266. https://doi.org/10.1016/S0034-4257(96)00067-3.

Hu, Q., Wu, W., Xia, T., Yu, Q., Yang, P., Li, Z., \& Song, Q. (2013). Exploring the Use of Google Earth Imagery and Object-Based Methods in 
Land Use/Cover Mapping. Remote Sens., 5(11), 6026-6042. https://doi.org/10.3390/rs5116026.

Huỳnh Trọng Nhân. (5/2/2021). Úng dụng kết quả phân tích ảnh viến thám Sentinel-2 trong quản lý thoát nước mặt các đô thị vùng ĐBSCL theo huóng bền vĩng.

http://vwsa.org.vn/vn/article/2260/ung-dung-ketqua-phan-tich-anh-vien-tham-sentinel-2-trongquan-ly-thoat-nuoc-mat-cac-do-thi-vung-dbscltheo-huong-ben-vung.html.

Hardin, P. J., Jackson, M. W., \& Otterstrom, S. M. (2007). Mapping, Measuring and Modeling Urban Growth. Geo-spatial Technologies in Urban Environments, Springer.

Lê Văn Trung \& Nguyễn Nguyên Vũ. (2018). Úng dụng viễn thám và GIS đánh giá xu thế đô thị hóa tại thành phố Cần Thơ. Tạp chí Phát triển Khoa học \& Công nghệ: Chuyên san khoa học trái đất \& môi trường, 2(1), 57-62.

Liu, L., Shi, L., Zhang, Z., and Zhao, X. (2015). Evaluating Urban Expansion of Beijing during 1973-2013, by using GIS and Remote Sensing. Geo-informatics in Resource Management and Sustainable Ecosystem, Springer.

Maktav, D., \& Erbek, F. (2005). Analysis of urban growth using multi-temporal satellite data in Istanbul, Turkey. International Journal of Remote Sensing, 26(4), 797-810. https://doi.org/10.1080/01431160512331316784.

Madhavan, B. B., Kubo, S., Kurisaki, N., \& Sivakumar, T. (2001). Appraising the anatomy and spatial growth of the Bangkok Metropolitan area using a vegetation-impervious-soil model through remote sensing. International Journal of Remote Sensing, 22(5), 789-806. https://doi.org/10.1080/01431160051060200.

Peng, X., Chen, X., \& Cheng, Y. (2010).

Urbanization and Its Consequences, in: Demography. Encyclopedia of Life Support Systems (EOLSS), UK.

Pajares, G., Sánchez-Beato, A., Cruz, J. M., \& Ruz, J. J. (2007). A Neural Network Model for Image Change Detection Based on Fuzzy Cognitive Maps. Pattern Recognition and Image Analysis, Springer.

Ramachandra, T., Bharath, H., \& Sowmyashree, M. (2013). Analysis of Spatial Patterns of Urbanisation Using Geoinformatics and Spatial Metrics. Theoretical and Empirical Researches in Urban Management, 8(4), 5-24.
Shalaby, A. (2012). Assessment of Urban Sprawl Impact on the Agricultural Land in the Nile Delta of Egypt Using Remote Sensing and Digital Soil Map. International Journal of Environment and Sciences, 1(4), 253-262.

Sintusingha, S. (2011). Bangkok's Urban Evolution: Challenges and Opportunities for Urban Sustainability, in: Sorensen, A., Okata, J. (Eds.), Megacities. Urban Form Governance and Sustainability, Springer. https://doi.org/10.1007/978-4-431-99267-7_7.

Sở Tài nguyên và Môi trường TP. Cần Thơ. (06/12/2019). Bản đồ ranh giới hành chính thành phố Cần Tho: https://www.invert.vn/ban-do-cantho-ar2522.

Tổng cục Thống kê. (2020). Kết quả toàn bộ tổng điều tra dân số và nhà ở năm 2019. Nhà xuất bản thống kê.

Trần Thị Vân. (2008). Đô thị hóa và chất lượng môi trường đô thị từ viễn thám các mặt không thấm: trường hợp Tp.HCM. Tạp chi Phát triển Khoa hoc và Công nghẹ, ĐHQG-HCM, 11(4), 1-7.

Tucker, C. J. (1979). Red and photographic infrared linear combinations for monitoring vegetation. Remote Sens. Environ, 8(2), 127150. https://doi.org/10.1016/00344257(79)90013-0.

Ủy ban nhân dân thành phố Cần Thơ. (24/05/2021). Cần Tho điều chinh quy hoạch chung đáp úng yêu cầu phát triển. https://moc.gov.vn/vn/tintuc/1184/67456/can-tho-dieu-chinh-quy-hoachchung-dap-ung-yeu-cau-phat-trien.aspx.

Wei, W., Yunjia, W., Qing, W., Dajun, L., \& Zhijie, W. (2012). Application of Decision Tree in Land Use Classification. International Conference on Informatics, Cybernetics, and Computer Engineering (ICCE2011), 42(5), 120-135. Melbourne, Australia.

Yang, X. (2010). Integration of Remote Sensing with GIS for Urban Growth Characterization. Geospatial Analysis and Modelling of Urban Structure and Dynamics, Springer.

Zha, Y., Gao, Y. \& Ni, S. (2003). Use of normalized difference built-up index in automatically mapping urban areas from TM imagery. International Journal of Remote Sensing, 24(3), 583-594. https://doi.org/10.1080/01431160304987. 